\title{
Electrical, magnetoresistance and magnetotransport properties of $\mathrm{Nd1}-\mathrm{xSrxMnO3}$
}

\begin{abstract}
The effects of $\mathrm{Sr}$ substitution on the electrical, magnetoresistance and magnetotransport properties of $\mathrm{Nd} 1-\mathrm{xSrxMnO} 3$ were studied. $\mathrm{Nd} 1-\mathrm{xSrxMnO} 3$ samples were prepared using the solid-state reaction method with $\mathrm{x}=0.12,0.152,0.22,0.252$ and 0.32 . All samples showed an orthorhombic structure, and no impurities were detected when the samples were examined using the X-ray diffraction method. The grain size was between $10 \mu \mathrm{m}$ and $16 \mu \mathrm{m}$ for all samples. The sample with $\mathrm{x}=0.32$ showed the smallest grain size and the lowest To value, where To reflects the MnOMn bond angle. As the Sr concentration increased, the grains grew into more pentagonal and hexagonal shapes, and the insulator-metal transition temperature, Tim, also increased from $131 \mathrm{~K}$ to $180 \mathrm{~K}$. The exceptions were the samples with $\mathrm{x}=0.152$ and 0.252 , where charge ordering was found at $120 \mathrm{~K}$. The samples with the most pentagonal and hexagonal shaped grains $(\mathrm{x}=0.32)$ had the highest Tim. The magnetoresistance $(\mathrm{MR})$ values were found to increase with increasing magnetic field. The sample with $\mathrm{x}=0.32$ showed the highest MR value (31.5\%), the highest Tim, the smallest grain size $(\sim 10 \mu \mathrm{m})$ and the least bending of the MnOMn bonding angle.
\end{abstract}

Keyword: Grain size; Electrical properties; Magnetic properties. 